\title{
Predicting energy requirement with pedometer- determined physical-activity level in women with chronic obstructive pulmonary disease
}

This article was published in the following Dove Press journal:

International Journal of COPD

15 June 2015

Number of times this article has been viewed

\author{
Nighat Farooqi' \\ Frode Slinde 2 \\ Maine Carlsson ${ }^{3}$ \\ Lena Håglin ${ }^{4}$ \\ Thomas Sandström' \\ 'Department of Public Health \\ and Clinical Medicine, Division of \\ Respiratory Medicine and Allergy, \\ Umeå University, Umeå, Sweden; \\ ${ }^{2}$ Department of Internal Medicine \\ and Clinical Nutrition, Sahlgrenska \\ Academy, University of Gothenburg. \\ Gothenburg, Sweden; ${ }^{3}$ Department \\ of Community Medicine and \\ Rehabilitation, Division of Geriatric \\ Medicine, Umeå University, Umeå, \\ Sweden; ${ }^{4}$ Department of Public Health \\ and Clinical Medicine, Division of \\ Family Medicine, Umeå University, \\ Umeå, Sweden
}

Background: In clinical practice, in the absence of objective measures, simple methods to predict energy requirement in patients with chronic obstructive pulmonary disease (COPD) needs to be evaluated. The aim of the present study was to evaluate predicted energy requirement in females with COPD using pedometer-determined physical activity level (PAL) multiplied by resting metabolic rate (RMR) equations.

Methods: Energy requirement was predicted in 18 women with COPD using pedometerdetermined PAL multiplied by six different RMR equations (Harris-Benedict; Schofield; World Health Organization; Moore; Nordic Nutrition Recommendations; Nordenson). Total energy expenditure (TEE) was measured by the criterion method: doubly labeled water. The predicted energy requirement was compared with measured TEE using intraclass correlation coefficient (ICC) and Bland-Altman analyses.

Results: The energy requirement predicted by pedometer-determined PAL multiplied by six different RMR equations was within a reasonable accuracy $( \pm 10 \%)$ of the measured TEE for all equations except one (Nordenson equation). The ICC values between the criterion method (TEE) and predicted energy requirement were: Harris-Benedict, ICC $=0.70,95 \%$ confidence interval (CI) 0.23-0.89; Schofield, ICC $=0.71,95 \%$ CI 0.21-0.89; World Health Organization, ICC $=0.74,95 \%$ CI $0.33-0.90$; Moore, ICC $=0.69,95 \%$ CI $0.21-0.88$; Nordic Nutrition Recommendations, ICC $=0.70,95 \%$ CI $0.17-0.89$; and Nordenson, ICC $=0.40,95 \%$ CI -0.19 to 0.77. Bland-Altman plots revealed no systematic bias for predicted energy requirement except for Nordenson estimates.

Conclusion: For clinical purposes, in absence of objective methods such as doubly labeled water method and motion sensors, energy requirement can be predicted using pedometer-determined PAL and common RMR equations. However, for assessment of nutritional status and for the purpose of giving nutritional treatment, a clinical judgment is important regarding when to accept a predicted energy requirement both at individual and group levels.

Keywords: pedometer-determined PAL, women with COPD, energy expenditure, DLW method

\section{Introduction}

Involuntary weight loss is common in patients with chronic obstructive pulmonary disease (COPD) and occurs in approximately $25 \%-50 \%$ of patients, ${ }^{1,2}$ and can be a result of an inadequate dietary intake combined with increased total energy expenditure (TEE). ${ }^{3}$ Low body weight (BW) and/or low fat-free mass (FFM) are related to increased mortality. ${ }^{4-6}$ Females with COPD seem to have higher prevalence of low body mass index (BMI) as well as low FFM index (FFMI) than male COPD patients. ${ }^{1}$ Malnutrition, prevalence of symptoms, susceptibility to smoking, frequency of exacerbations, impairment of quality of life, hyper-responsiveness of airways, triggering
Correspondence: Nighat Farooqi Department of Respiratory Medicine and Allergy, Umeå University Hospital, SE-90I 85, Umeå, Sweden

$\mathrm{Tel}+46907852269$

Fax +4690773817

Email nighat.farooqi@lung.umu.se 
stimuli, response to treatment, and depression are more often seen in females with COPD. ${ }^{7}$ Females seem also to be more predisposed to adverse respiratory effects of tobacco smoking and develop COPD at an earlier age, and a sex bias in the diagnosis of COPD and use of health care exists. ${ }^{8}$

Energy expenditure in COPD patients has been assessed in many studies. ${ }^{9-13}$ Some have reported TEE in COPD patients using doubly labeled water (DLW), ${ }^{9,10,13}$ and others have used different motion sensors. ${ }^{10,12}$ DLW is the gold standard for assessment of TEE. It is also used as a measure of energy requirement when a person is weight-stable, but its high cost and the technical expertise required for the implementation and analysis complicates its use in daily clinical settings. Access to validated motion sensors for assessment of TEE/energy requirement in the clinical praxis is also very limited. Other studies have calculated TEE in COPD patients using predicted resting metabolic rate (RMR) and predefined activity factors. $^{2}$

Physical activity is an important component in TEE. Low physical activity has been suggested as a strong predictor of death in COPD. ${ }^{14}$ In COPD patients, physical activity has been assessed using different devices, from simple pedometers to more complex motion sensors. ${ }^{12,15}$ Pedometers are inexpensive, feasible, and easily available devices. The Yamax Digi-Walker SW-200 (Yamasa Tokei Keiki Co. Ltd, Tokyo, Japan) is a pedometer that is widely used in research and has been shown to be valid. ${ }^{16,17}$ It is a mechanical, uniaxial, spring-levered pedometer that counts the number of steps by vertically displacing a lever arm inside the unit when an ambulatory movement generates a force of $\geq 0.35 \mathrm{~g}$. It is worn on the anterior side of the hip and the anterolateral side of the knee on the right side. Accumulated numbers of steps are shown on a digital screen. Numbers of steps taken/day have been translated to define physical activity and subsequently classify if a person is sedentary or active. ${ }^{18}$ Studies have often assessed activity energy expenditure from the pedometers. ${ }^{16,19}$ To date, to our knowledge, no studies evaluating pedometer-determined physical activity level (PAL) have been conducted.

To be able to achieve energy balance through nutritional intervention, one must know the patients energy expenditure. In the absence of criterion methods and validated motion sensors, we need to evaluate simple methods to predict energy requirement. Studies considering the evaluation of predicting energy expenditure are scarce in COPD patients. Therefore, the aim of the present study was to evaluate predicted energy requirement in females with COPD using pedometer-determined PAL multiplied by RMR equations.
We hypothesized that energy requirement can be predicted within reasonable limits using pedometer-determined PAL multiplied by RMR equations.

\section{Materials and methods Study design and protocol}

This cross-sectional study was conducted in the Department of Public Health and Clinical Medicine, Division of Respiratory Medicine and Allergy, and the Clinical Research Center at Umeå University Hospital in Umeå, Sweden. Each study patient was instructed not to engage in any rigorous physical activity and not to eat after $11 \mathrm{pm}$ on the day prior to the testing day. At the hospital, a blood sample was collected from each patient for measurements of arterial oxygen tension, arterial carbon dioxide tension, and $\mathrm{O}_{2}$ saturation. The BW, height, FFM, and RMR of each patient were also measured. Following the RMR measurements, breakfast was served. FFM was measured by dual-energy $\mathrm{X}$-ray absorptiometry. The total study duration was 14 days for each participant. Pulmonary function tests were conducted within the first 3 months following the initial 14-day study period.

TEE was measured over 14 days by DLW method. Simultaneously, PAL was assessed by a pedometer. A home visit was performed between days 8 and 10 of the study. The purpose of the home visit was to ensure the appropriate collection and storage of urine samples, and to register the accumulated number of steps from the pedometer.

The Ethical Review Board of Umeå University approved the study, and written informed consent was obtained from each of the patients prior to their participation in the study.

\section{Subjects}

Nineteen women with COPD attending the outpatient clinic in the Department of Medicine, Respiratory Medicine and Allergy Unit at Umeå University Hospital in Umeå, Sweden, were identified and recruited if they fulfilled the inclusion criteria.

\section{Inclusion criteria}

Patients with clinically stable COPD (Global Initiative for Chronic Obstructive Pulmonary Disease, ${ }^{20}$ stage II and III) and a BMI between 18.5 and $30.0 \mathrm{~kg} / \mathrm{m}^{2}$, ${ }^{21}$ were selected. BWs and heights were measured, and BMI was calculated for each patient prior to her inclusion in the study.

\section{Exclusion criteria}

Patients with a history of oxygen therapy, insulin-treated diabetes, thyroid dysfunction, or myopathic or neoplastic disease were excluded from the study. 


\section{Anthropometry}

Patients' BW was measured at the start and at the end of the 14-day study period, to the nearest $0.1 \mathrm{~kg}$, using a digital scale, while the patient was wearing light clothing. The height of each patient was measured at the start of the study to the nearest $0.5 \mathrm{~cm}$ using a horizontal headboard with an attached wall-mounted metric scale. BMI was then calculated based on these measurements (BW in $\mathrm{kg} /$ height in $\mathrm{m}^{2}$ ). FFM was measured at the start of the study by dual-energy X-ray absorptiometry using a total body scanner (Lunar Prodigy, version 13.31; Scanex Medical Systems, Helsingborg, Sweden).

\section{Pulmonary function measurements}

Dynamic and static pulmonary function tests were performed (Jaeger, MasterScreen Body, and MasterScreen PFT; CareFusion, Höchberg, Germany). An automatic analyzer was used to measure arterial oxygen tension, carbon dioxide tension, and $\mathrm{O}_{2}$ saturation in samples of arterial blood that were drawn from the radial artery using a syringe.

\section{RMR}

\section{Indirect calorimetry}

The RMR was measured by indirect calorimetry (Deltatrac ${ }^{\text {TM }}$ II Metabolic Monitor; Datex, Helsinki, Finland) using a ventilated hood system. Patients arrived on the test day in a fasting state, and the RMR of each patient was measured for 30 minutes after the patients had rested in a supine position for 30 minutes. All patients were awake during measurement collections. Prior to each measurement, the equipment was calibrated with gas mixtures $\left(\mathrm{O}_{2}\right.$ and $\left.\mathrm{CO}_{2}\right)$ according to the manufacturer's instructions. All measurements were performed at a room temperature of $22^{\circ} \mathrm{C}-24^{\circ} \mathrm{C}$. The results shown here are based on the last 25 minutes of measurement. The RMR measured by indirect calorimetry was the criterion method for RMR.

\section{Prediction equations}

The RMR was also estimated from six different commonly used prediction equations for women:

1. Harris-Benedict: ${ }^{22}$

$655.1+(9.563 \times$ weight in $\mathrm{kg})+(1.850 \times$ height in $\mathrm{cm})-(4.676 \times$ age in years $) \mathrm{kcal}$

2. Schofield: ${ }^{23}$

30-60 years: $34 \times$ weight in $\mathrm{kg}+3,538 \mathrm{~kJ}$

$>60$ years: $38 \times$ weight in $\mathrm{kg}+2,755 \mathrm{~kJ}$
3. World Health Organization (WHO): ${ }^{24}$

30-60 years: $8.7 \times$ weight in $\mathrm{kg}+829 \mathrm{kcal}$

$>60$ years: $10.5 \times$ weight in $\mathrm{kg}+596 \mathrm{kcal}$

4. Moore: $:^{25}$

$$
14.1 \times \text { weight in } \mathrm{kg}+515 \mathrm{kcal}
$$

5. Nordic Nutrition Recommendations (NNR), (based on Henry): ${ }^{26}$

$$
\begin{aligned}
& \text { 31-60 years: } 0.0407 \times \text { weight in } \mathrm{kg}+2.90 \mathrm{MJ} \\
& 61-70 \text { years: } 0.0429 \times \text { weight in } \mathrm{kg}+2.39 \mathrm{MJ} \\
& >70 \text { years: } 0.0417 \times \text { weight in } \mathrm{kg}+2.41 \mathrm{MJ}
\end{aligned}
$$

6. Nordenson: ${ }^{27}$

$$
1,856+76.0 \times \mathrm{FFM} \text { in } \mathrm{kg} \mathrm{kJ}
$$

RMR calculated above was converted to $\mathrm{kJ} /$ day by using a conversion factor of $1 \mathrm{kcal}=4.184 \mathrm{~kJ}$ and $1 \mathrm{MJ}=1,000 \mathrm{~kJ}$.

\section{Energy requirement and PAL DLW}

TEE was measured using DLW as described elsewhere. ${ }^{13}$ The DLW method involves administering a dose of stable isotopes of deuterium $\left({ }^{2} \mathrm{H}\right)$ and oxygen-18 $\left({ }^{18} \mathrm{O}\right)$, and subsequently measuring the rates of elimination of these isotopes from the body over time. The relationship between pool size deuterium $\left(\mathrm{N}_{\mathrm{D}}\right)$ and pool size oxygen-18 $\left(\mathrm{N}_{\mathrm{O}}\right)$ was used as a quality measurement. The acceptable range of this relationship $\left(\mathrm{N}_{\mathrm{D}} / \mathrm{N}_{\mathrm{O}}\right)$ has been proposed by the International Atomic Energy Agency to be between 1.015 and 1.060. ${ }^{28}$ The respiratory quotient was set at 0.85 for calculations of the energy equivalence of $\mathrm{CO}_{2}$ produced. ${ }^{29}$ TEE measured by DLW method was the criterion method for evaluation of predicted energy requirement.

The criterion PAL was calculated from the energy expenditure measured by DLW ( $\left.\mathrm{TEE}_{\mathrm{DLW}}\right)$ method and RMR measured by indirect calorimetry $\left(\mathrm{RMR}_{\mathrm{IC}}\right)$.

$$
\mathrm{PAL}=\mathrm{TEE}_{\mathrm{DLW}} / \mathrm{RMR}_{\mathrm{IC}}
$$

\section{Pedometer}

PAL was also determined by a pedometer, the Yamax DigiWalker SW-200 (Yamasa Tokei Keiki Co. Ltd) that was placed on the belt or waistband, in the midline of the thigh, consistent with the manufacturer's recommendations. The patients wore the pedometer during the day time for 14 days. 
They were instructed to wear the pedometer as soon as they got out of bed and take it off when they went to bed in the evening, and were advised not to use it while showering/ bathing. Thorough oral and written instructions regarding the appropriate use of the pedometer were provided. The patients were also instructed to keep a record of the times that they were not wearing this device, including a list of the activities performed during those periods.

Accumulated numbers of steps taken until the home visit were registered and the pedometer was reset. Then, again, the accumulated numbers of steps taken were registered at the end of the study period. The registered numbers of steps from two time points were added and an average number of steps/day were calculated.

Pedometer-determined PAL was calculated in two stages. First, the patients were classified into different activity categories based on their average number of steps taken/ day as proposed by others. ${ }^{18}$ These authors have presented different step-defined physical activity categories based on pedometer data (steps/day). In the second stage, PAL values were estimated according to the patient's physical activity category. ${ }^{30}$ Since all the patients were retired at the time of the study, no differentiation in "work and leisure" time was made. Patients taking $<5,000$ steps/day were categorized as "sedentary" implying that the patients have "very light" physical activity throughout the day, hence a PAL value of 1.4; those taking 5,000-7,499 steps/day were categorized as "low active" having "light" physical activity indicating a PAL value of 1.6; and those who took 7,500-9,999 steps/day were categorized as "somewhat active" having "moderate" physical activity, thus a PAL value of 1.8. ${ }^{18,30}$

Energy requirement was estimated from the abovementioned six RMR equations and estimated PAL from the pedometer. Each RMR prediction equation was multiplied by pedometer-determined PAL for an assessment of energy requirement $(\mathrm{RMR}$ from prediction equations $\times \mathrm{PAL}$ pedometer-determined).

The accuracy of individually predicted energy requirements was defined as the percentage of participating individuals whose predicted energy requirement was within $\pm 10 \%$ of measured TEE. ${ }^{31}$

\section{Smoking habits}

Information about smoking habits was collected through interviews and was recorded as the number of pack years.

\section{Statistical analysis}

To be included in the present analysis, each patient had to wear the pedometer for at least 12 days. When data for any day of the 14-day measurement period were missing, the average numbers of steps obtained on the measured days were used in the analysis. Measured RMR from indirect calorimetry and TEE from DLW were calculated as the mean value/day.

The data were analyzed using the statistical program SPSS version 21.0 (Statistical Package for the Social Sciences; IBM Corporation, Armonk, NY, USA). Descriptive statistics, such as means, standard deviations, and minimum and maximum values, were used. To assess differences between the criterion methods and predicted values of RMR, PAL, and energy requirement, paired $t$-test was used. To determine the strength of the relationship between the criterion and the predicted methods, Pearson's correlation coefficient was used. ${ }^{32}$ To examine the degree of agreement between criterion and predicted estimates of RMR, PAL, and energy requirement, we calculated intraclass correlation coefficients (ICCs) assuming a two-way analysis of variance. ${ }^{33}$ For these correlation analyses, the closer the correlation is to 1.0 , the lower the within-subject variance and the greater the concordance between the estimates. Bland-Altman plots were constructed to examine the degree of systematic bias (ie, if there is any relationship between the magnitude of energy expenditure and differences between the methods) and to calculate the limits of agreement between the predicted methods and the criterion method, DLW.

Prediction accuracy at individual level was defined as the percentage of participants in the study group whose energy requirement was predicted to within $\pm 10 \%$ of measured TEE. ${ }^{29}$ The level of significance was set at 0.05 .

\section{Results}

The general characteristics of the participating women with COPD are shown in Table 1. Eighteen women had a FFMI below normal value, $\geq 15 \mathrm{~kg} / \mathrm{m}^{2}{ }^{1}$ Thirteen women $(68 \%)$ had quit smoking, and six were current smokers.

TEE measured by DLW and RMR measured by indirect calorimetry was collected from all 19 patients. Pedometer data was collected from 19 patients. One woman did not wear the pedometer as instructed and the pedometer protocols were not filled correctly. Therefore, one woman was excluded from the data analysis. Pulmonary function tests were performed within the 3 months following the 14-day study period in 16 of the women who participated in the study. Of the three remaining patients, one died of heart failure, one moved to southern Sweden, and one refused to participate. The overall compliance with regards to participation and execution of different tasks in this study was excellent. The $\mathrm{N}_{\mathrm{D}} / \mathrm{N}_{\mathrm{O}}$ in DLW method was between 1.018 and 1.048 . 
Table I General characteristics of women with COPD

\begin{tabular}{llll}
\hline & N & Mean \pm SD & Min-Max \\
\hline Age, years & 19 & $69.2 \pm 6.0$ & $59.7-80.0$ \\
Weight, kg & 19 & $63.5 \pm 10.7$ & $46.8-88.0$ \\
$\mathrm{BMI}, \mathrm{kg} / \mathrm{m}^{2}$ & 19 & $24.5 \pm 3.5$ & $18.5-30.0$ \\
$\mathrm{FFMI}, \mathrm{kg} / \mathrm{m}^{2}$ & 19 & $12.6 \pm 1.3$ & $10.3-16.0$ \\
Number of pack years & 19 & $27.7 \pm 9.0$ & $14-42$ \\
Arterial $\mathrm{PCO}_{2}, \mathrm{kPa}$ & 16 & $5.2 \pm 0.6$ & $4.3-6.7$ \\
Arterial $\mathrm{PO}_{2}, \mathrm{kPa}$ & 16 & $10.2 \pm 2.9$ & $4.4-18.4$ \\
Arterial $\mathrm{O}_{2}$ saturation & 16 & $92.9 \pm 9.2$ & $59.5-98.8$ \\
$\mathrm{FEV}_{1} / \mathrm{FVC}$, liters & 16 & $0.43 \pm 0.12$ & $0.24-0.65$ \\
$\mathrm{FEV}_{1}$, liters & 16 & $1.14 \pm 0.32$ & $0.72-1.7$ \\
$\mathrm{FEV}_{1}, \%$ predicted value & 16 & $56.0 \pm 15.0$ & $30-78$ \\
\hline $\mathrm{A}^{2}$. & &
\end{tabular}

Abbreviations: BMI, body mass index; FEV, forced expiratory volume; FEV $_{1}$, forced expiratory volume in I second; FFMI, fat-free mass index; FVC, forced vital capacity; Min-Max, minimum-maximum; $\mathrm{pCO}_{2}$, carbon dioxide tension; $\mathrm{PO}_{2}$, oxygen tension; SD, standard deviation.

\section{PAL}

The average number of steps taken daily was $3,757 \pm 2,065$ (minimum-maximum: 1,530-8,310). Estimated PAL from the pedometer was lower by $13.6 \%$ than the measured criterion PAL (Table 2). The correlation between the predicted and the measured PAL was moderate and the ICC was low and nonsignificant (Table 3 ). ${ }^{32,33}$

Table 2 Energy expenditure and physical activity level assessed by different methods in women with COPD $(\mathrm{N}=18)$

\begin{tabular}{|c|c|c|}
\hline & Mean \pm SD & Min-Max \\
\hline \multicolumn{3}{|l|}{$\mathrm{RMR}, * \mathrm{~kJ} \cdot \mathrm{d}^{-1}$} \\
\hline Indirect calorimetry & $4,832 \pm 548$ & $4,207-6,248$ \\
\hline Harris-Benedict & $5,210 \pm 480$ & $4,455-6,425$ \\
\hline Schofield & $5,189 \pm 407$ & $4,533-6,099$ \\
\hline WHO & $5,302 \pm 470$ & $4,545-6,353$ \\
\hline Moore & $5,934 \pm 632$ & $4,916-7,346$ \\
\hline NNR & $5,|3| \pm 504$ & $4,362-6,482$ \\
\hline Gothenburg & $4,370 \pm 349$ & $3,854-5,459$ \\
\hline \multicolumn{3}{|l|}{ Physical activity level } \\
\hline $\mathrm{TEE}_{\mathrm{DLW}} / \mathrm{RMR}_{\mathrm{IC}}$ & $1.69 \pm 0.147$ & $1.5-2.1$ \\
\hline Pedometer-determined & $1.46 \pm 0.134$ & $1.4-1.8$ \\
\hline \multicolumn{3}{|l|}{ TEE, $\mathrm{kJ} \cdot \mathrm{d}^{-1}$} \\
\hline Doubly labeled water & $8,114 \pm 907$ & $6,3 \mid I-10,258$ \\
\hline Harris-Benedict & $7,607 \pm 1,222$ & $6,237-11,566$ \\
\hline Schofield & $7,57 \mid \pm I, 097$ & $6,347-10,978$ \\
\hline WHO & $7,738 \pm I, \mid 89$ & $6,362-11,436$ \\
\hline Moore & $8,664 \pm I, 469$ & $6,882-13,223$ \\
\hline NNR & $7,494 \pm I, 265$ & $6,106-11,667$ \\
\hline Nordenson & $6,387 \pm I, 047$ & $5,395-9,827$ \\
\hline
\end{tabular}

Note: *Data represent the average of the last 25 minutes of measurement. Abbreviations: Min-Max, minimum-maximum; NNR, Nordic Nutrition Recommendations; RMR, resting metabolic rate; $R M R_{1 C}$, RMR measured by indirect caloimetry; SD, standard deviation; TEE, total daily energy expenditure; $T_{E E_{D L W}}$ energy expenditure measured by doubly labeled water; WHO, World Health Organization.

\section{RMR}

Measured and predicted RMRs are presented in Table 2. Five of six prediction equations overestimated RMR compared to measured RMR by indirect calorimetry, and the overestimation was between $6.2 \%$ and $22.8 \%$. RMR assessed by Nordenson equation showed an underestimation of $9.6 \%$ compared to the indirect calorimetry. Table 3 shows that the ICC between indirect calorimetry and prediction equations were moderate for five RMR equations. ${ }^{33}$

\section{Energy requirement}

There was large variation in the measured and predicted energy requirement (Table 2). Five of six prediction equations underestimated energy requirement. Compared to the criterion method, underestimation of energy requirement was $6.2 \%$ by Harris-Benedict, $6.7 \%$ by Schofield, $4.6 \%$ by WHO, $7.6 \%$ by NNR, and $21.3 \%$ as assessed by Nordenson. Energy requirement was overestimated by $6.8 \%$ when assessed by Moore compared to the criterion method. The predicted energy requirement correlated significantly with the criterion DLW method for all six RMR equations (Table 3). ${ }^{32}$ The ICC values were $\geq 0.70$ in four of six predicted TEE methods (Table 3). In the Bland-Altman plots, the values were more evenly distributed around the mean difference for TEE assessed by Schofield, WHO, Moore, and NNR (Figure 1B-E). The differences between the criterion method and Nordenson estimates were significantly correlated with the magnitude of TEE ( $r=-0.54, P=0.02$ ), exhibiting an increase in overestimation of predicted TEE with increasing TEE (Figure 1F).

The percentage of participants whose predicted energy requirement was within $\pm 10 \%$ of measured TEE varied among the methods evaluated. When energy requirement was predicted by WHO method, $67 \%$ of women were within $\pm 10 \%$ of measured TEE; for energy requirement predicted by Harris-Benedict, Moore, and NNR, $50 \%$ of women were within $\pm 10 \%$ of the individually measured TEE; for energy requirement predicted by Schofield and Nordenson, $56 \%$ and $22 \%$ of women, respectively, were within $\pm 10 \%$ of measured TEE with the DLW method. ${ }^{31}$

\section{Discussion}

In the present study, we have shown that predicted energy requirement assessed by pedometer-determined PAL and commonly used RMR equations correlated significantly for all the six equations and had a significant agreement for five equations with the criterion method, DLW, in women with COPD. The predicted energy requirement by WHO equation multiplied by pedometer-determined PAL gave better 
Table 3 Energy expenditure and physical activity level estimates from the criterion and test methods using different statistical analysis in women with COPD ( $\mathrm{N}=19)$

\begin{tabular}{|c|c|c|c|c|c|c|}
\hline & \multicolumn{2}{|c|}{$\begin{array}{l}\text { Difference of the means } \pm \text { SD } \\
\text { (criterion-predicted) }\end{array}$} & \multicolumn{2}{|c|}{ Pearson's correlation } & \multicolumn{2}{|c|}{$\begin{array}{l}\text { Intraclass correlations } \\
\text { coefficient }\end{array}$} \\
\hline & $\mathbf{k J} \cdot \mathbf{d}^{-1}$ & $P$-value & $r$ & $P$-value & $r$ & $95 \% \mathrm{Cl}$ \\
\hline \multicolumn{7}{|l|}{$\mathrm{RMR},{ }^{*} \mathrm{~kJ} \cdot \mathrm{d}^{-1}$} \\
\hline \multicolumn{7}{|l|}{ Criterion (IC) } \\
\hline Harris-Benedict & $-379 \pm 504$ & 0.005 & 0.53 & 0.025 & 0.59 & -0.05 to 0.85 \\
\hline Schofield & $-358 \pm 510$ & 0.009 & 0.46 & 0.054 & 0.52 & -0.13 to 0.81 \\
\hline WHO & $-47 I \pm 533$ & 0.002 & 0.46 & 0.054 & 0.49 & -0.19 to 0.80 \\
\hline Moore & $-1,102 \pm 617$ & $<0.0001$ & 0.46 & 0.054 & 0.29 & -0.20 to 0.68 \\
\hline NNR & $-299 \pm 511$ & 0.024 & 0.53 & 0.023 & 0.64 & 0.08 to 0.86 \\
\hline Nordenson & $462 \pm 483$ & 0.001 & 0.49 & 0.038 & 0.46 & -0.22 to 0.79 \\
\hline \multicolumn{7}{|l|}{ Physical activity level } \\
\hline \multicolumn{7}{|l|}{ Criterion (TEE $\left.\mathrm{DLW} / \mathrm{RMR}_{\mathrm{IC}}\right)$} \\
\hline Pedometer-determined ( $\left.\mathrm{PAL}_{\mathrm{ped}}\right)$ & $0.23 \pm 0.145$ & $<0.001$ & 0.47 & 0.046 & 0.34 & -0.23 to 0.72 \\
\hline \multicolumn{7}{|l|}{ TEE, $k J \cdot d^{-1}$} \\
\hline \multicolumn{7}{|l|}{ Criterion (DLW) } \\
\hline Harris-Benedict $\times \mathrm{PAL}_{\text {ped }}$ & $507 \pm 973$ & 0.04 & 0.62 & 0.006 & 0.70 & 0.23 to 0.89 \\
\hline Schofield $\times \mathrm{PAL}_{\mathrm{ped}}$ & $543 \pm 876$ & 0.018 & 0.63 & 0.005 & 0.71 & 0.21 to 0.89 \\
\hline $\mathrm{WHO} \times \mathrm{PAL}_{\mathrm{ped}}$ & $376 \pm 933$ & 0.106 & 0.63 & 0.005 & 0.74 & 0.33 to 0.90 \\
\hline Moore $\times \mathrm{PAL}_{\mathrm{ped}}$ & $-550 \pm I, \mid 37$ & 0.056 & 0.63 & 0.005 & 0.69 & 0.21 to 0.88 \\
\hline $\mathrm{NNR} \times \mathrm{PAL}_{\mathrm{ped}}$ & $620 \pm 975$ & 0.015 & 0.64 & 0.004 & 0.70 & 0.17 to 0.89 \\
\hline Nordenson $\times \mathrm{PAL}_{\text {ped }}$ & $\mathrm{I}, 727 \pm 864$ & $<0.0001$ & 0.62 & 0.006 & 0.40 & -0.19 to 0.77 \\
\hline
\end{tabular}

Note: *Data represent the average of the last 25 minutes of measurement.

Abbreviations: $\mathrm{Cl}$, confidence interval; DLW, doubly labeled water; IC, indirect calorimetry; NNR, Nordic Nutrition Recommendations; PAL ${ }_{\text {ped, }}$ pedometer-determined physical activity level; RMR, resting metabolic rate; $\mathrm{RMR}_{\mathrm{IC}}, \mathrm{RMR}$ measured by indirect calorimetry; $\mathrm{SD}$, standard deviation; TEE, total daily energy expenditure; TEE ${ }_{\mathrm{DLW}}$, energy expenditure measured by DLW; WHO, World Health Organization.

estimates at both group and individual levels than other validated equations.

Although predicted energy requirement by five of six validated RMR prediction equations multiplied by pedometerdetermined PAL had a significant agreement with measured TEE by DLW, ${ }^{33}$ the confidence intervals were wide, and there was a considerable variation. Wide confidence intervals could be because of small sample size. The variation in predicted energy requirement could partly be due to the RMR equations used, as has been shown in many reports in different populations. ${ }^{2,25,27,31,34-37}$ Similar to our findings, Slinde et al have reported that energy requirements can be assessed using the WHO equation at group level. ${ }^{2}$ They assessed energy requirements using the WHO equation multiplied by a factor of 1.7, whereas we have used pedometer-determined PAL. Moore et al derived an RMR prediction equation in COPD patients. ${ }^{25}$ Compared to indirect calorimetry, predicted RMR by Moore's equation was overestimated by $23 \%$ in the present study. This difference could be due to different COPD patient groups studied. They included patients with mild COPD to patients with acute respiratory failure, whereas in our study only patients with stable COPD (stage II and III) were included. RMR equation by Nordenson et al is a new validated disease-specific equation in underweight COPD patients and is based on FFM rather than $\mathrm{BW} .{ }^{27}$ In the present study, the Nordenson equation underestimated RMR by 9.6\% . This could be because COPD patients in our study had a lower FFMI than patients in the Nordenson et al study. In fact, only one woman had a FFMI in normal range in our study. ${ }^{1}$ The variability in assessment of RMR by different prediction equations could be due to: 1) discrepancy between the characteristics of groups upon which these predictive equations are based and current populations; and 2) differences in the time line of when these studies were conducted. Despite the variation in predicted RMR by different equations evaluated in this study, five out of six equations predicted RMR within a reasonable accuracy, ie, $\pm 10 \%$ of the measured RMR at group level. ${ }^{31}$

To our knowledge, to date, this is the first time PAL has been determined based on average number of steps taken daily. In this study, we obtained acceptable values of predicted energy requirement in five of six RMR equations multiplied by pedometer-determined PAL. However, there was a considerable underestimation of pedometerdetermined PAL compared to the criterion PAL. There could be a few reasons for this underestimation. Firstly, 
A

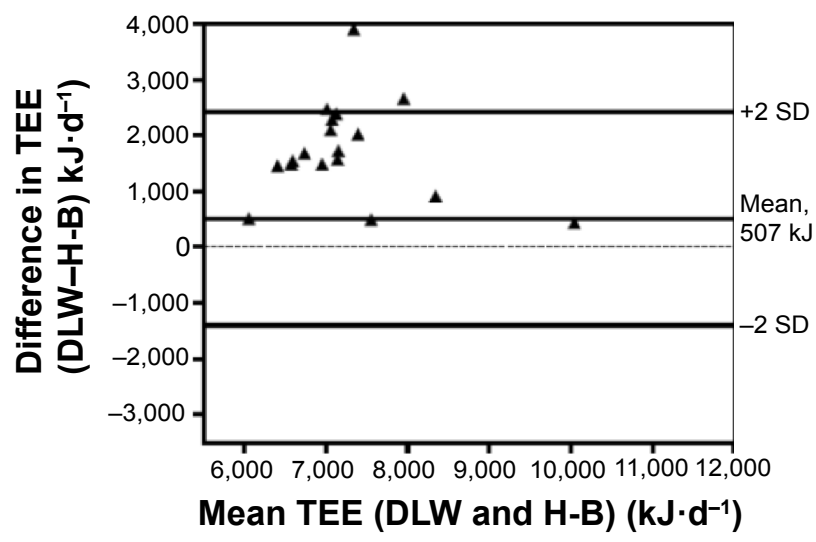

C

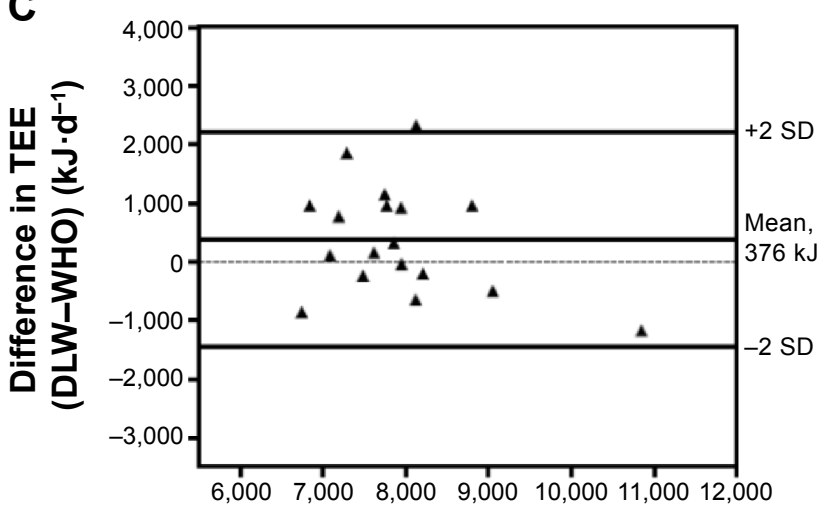

Mean TEE (DLW and WHO) $\left(\mathrm{kJ} \cdot \mathrm{d}^{-1}\right)$

E

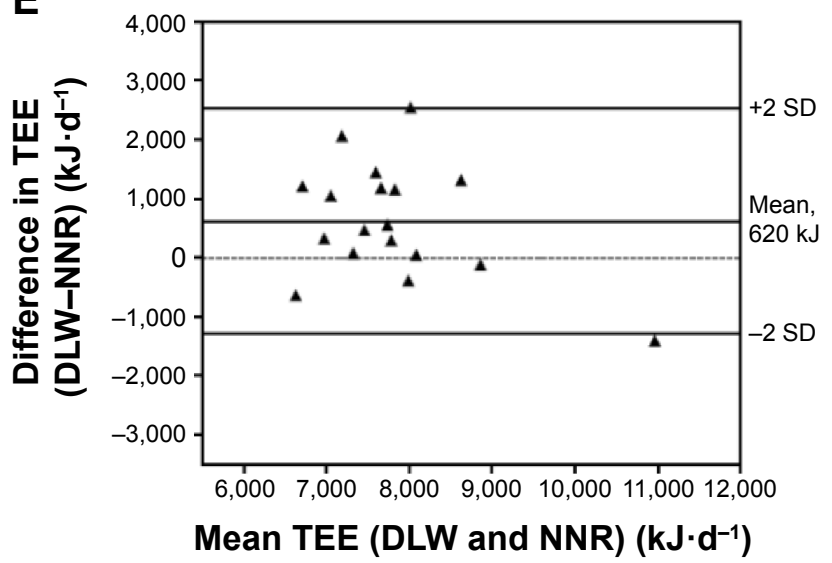

B

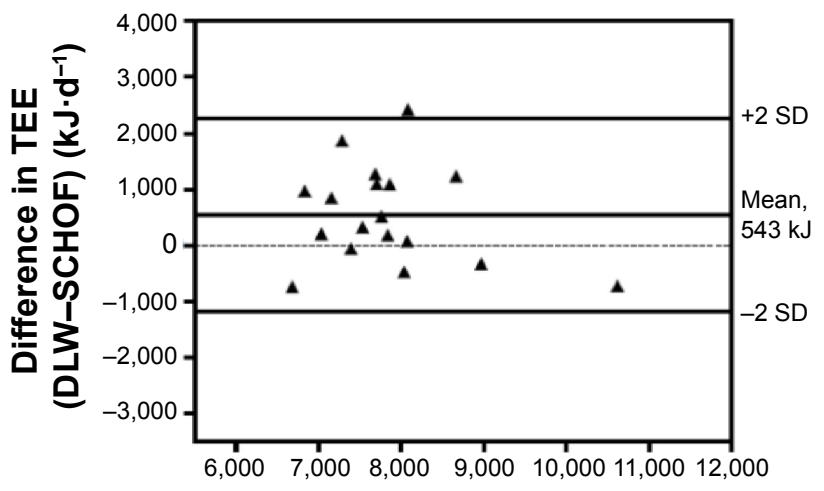

Mean TEE (DLW and SCHOF) $\left(\mathrm{kJ} \cdot \mathrm{d}^{-1}\right.$ )

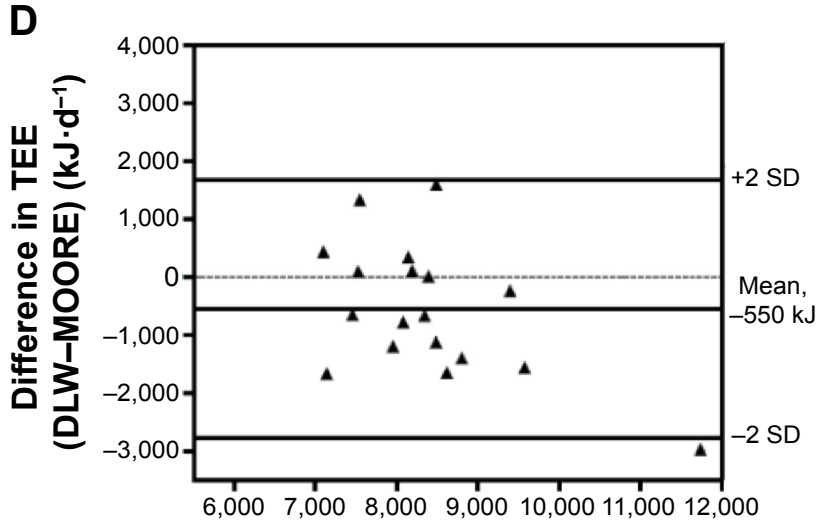

Mean TEE (DLW and MOORE) $\left(\mathrm{kJ} \cdot \mathrm{d}^{-1}\right)$

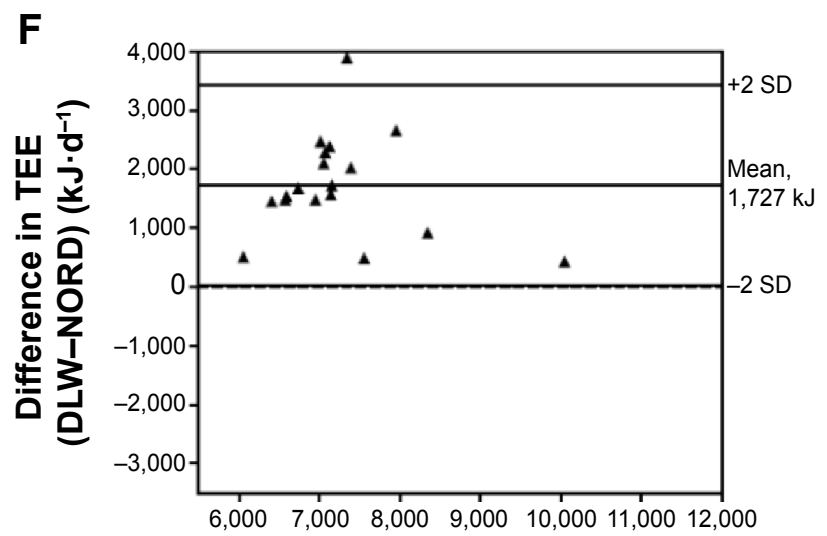

Mean TEE (DLW and NORD) $\left(\mathrm{kJ} \cdot \mathrm{d}^{-1}\right)$

Figure I Bland-Altman plots.

Notes: Bland-Altman plots showing the differences in the mean TEE between the DLW method and predicted energy requirement by (A) the H-B RMR equation multiplied by pedometer-determined PAL, (B) the SCHOF RMR equation multiplied by pedometer-determined PAL, (C) the WHO RMR equation multiplied by pedometer-determined PAL, (D) the MOORE RMR equation multiplied by pedometer-determined PAL, (E) the NNR RMR equation multiplied by pedometer-determined PAL, and (F) the NORD RMR equation multiplied by pedometer-determined PAL in 18 women with COPD.

Abbreviations: DLW, doubly labeled water; H-B, Harris-Benedict; NNR, Nordic Nutrition Recommendations; NORD, Nordenson; PAL, physical activity level; RMR, resting metabolic rate; SCHOF, Schofield; SD, standard deviation; TEE, total daily energy expenditure; WHO, World Health Organization.

assigning PAL values based only on the number of steps taken may have contributed to some discrepancy between the calculated and measured PAL. Secondly, the study patients might have had other activities such as cycling, swimming, or upper body movements that are not registered as steps but contribute to increased PAL. Lastly, pedometers have been shown to have less accuracy for step counting at slower walking speed in chronic respiratory disease patients and in healthy subjects. ${ }^{19,38}$ It is speculated that walking at slower speed is common in COPD patients 
especially with a severe form of disease. COPD patients are often less active and have very low median values for steps/day. ${ }^{39}$ Besides, the pedometer used in this study needs a force of $\geq 0.35 \mathrm{~g}$ to register a step. Considering these factors, there is a probability that all the steps taken by the study patients might not have been registered, thus resulting in lower pedometer-determined PAL than actual PAL. Nevertheless, we speculate that using pedometerdetermined PAL gives a better estimate than using a theoretical PAL value. Furthermore, Tudor-Locke et al have presented aggregated evidence of convergent validity and conclude that pedometers can be used for assessment of physical activity in both research and practice. ${ }^{40}$

There are some limitations in this study. One of the limitations is the small sample size of the study. Another limitation is that we did not test the ability of the pedometer to register steps at different speeds prior to collection of data. Further studies including a larger number of participants and all the stages of COPD are required.

\section{Conclusion}

In this study, we have shown that for clinical purposes, in absence of objective methods such as DLW method and motion sensors, energy requirement can be predicted within reasonable limits using pedometer-determined PAL multiplied by RMR equations in women with COPD. The predicted energy requirement by WHO equation multiplied by pedometer-determined PAL gave better estimates both at group and individual level than other validated equations. However, we believe that for assessment of nutritional status and for the purpose of giving nutritional treatment, a clinical judgment will play an important role regarding when to accept estimated energy requirement using predictive RMR equations and pedometer-determined PAL both at individual and group levels in females with COPD. If energy requirement is predicted in a clinical setting and used as a base for nutritional treatment, it is important to regularly follow up the results of the treatment.

\section{Acknowledgments}

The authors would like to thank the staff at the research laboratory and all of the nurses at the Respiratory Medicine and Allergy Unit at Umeå University Hospital for taking blood samples, and for their help and support during data collection. The authors would also like to thank the technical staff of the University of Gothenburg for conducting the urine analyses and the staff at the Clinical Research Center at Umeå University for their cooperation during the study period.

\section{Disclosure}

The authors report no conflicts of interest in this work.

\section{References}

1. Vermeeren MA, Creutzberg EC, Schols AM, et al. Prevalence of nutritional depletion in large out-patient population of patients with COPD. Respir Med. 2006;100:1349-1355.

2. Slinde F, Grönberg AM, Svantesson U, Hulthén L, Larsson S. Energy expenditure in chronic obstructive pulmonary disease-evaluation of simple measures. Eur J Clin Nutr. 2011;65(12):1309-1313.

3. Schols AM, Soeters PB, Mostert R, Saris WH, Wouters EF. Energy balance in chronic obstructive pulmonary disease. Amer Rev Resp Dis. 1991;143:1248-1252.

4. Schols AM, Broekhuizen R, Weling-Scheepers CA, Wouters EF. Body composition and mortality in chronic obstructive pulmonary disease. Am J Clin Nutr. 2005;82:53-59.

5. Slinde F, Grönberg A, Engström CP, Rossander-Hulthén L, Larsson S. Body composition by bioelectrical impedance predicts mortality in chronic obstructive pulmonary disease. Respir Med. 2005; 99:1004-1009.

6. King DA, Cordova F, Scharf SM. Nutritional aspects of chronic obstructive pulmonary disease. Proc Am Thorac Soc. 2008;5:519-523.

7. Cote CG, Chapman KR. Diagnosis and treatment considerations for women with COPD. Int J Clin Pract. 2009;63:486-493.

8. Chapman KR. Chronic obstructive pulmonary disease: are women more susceptible than men? Clin Chest Med. 2004;25:331-341.

9. Baarends EM, Schols AM, Pannemans DL, Westerterp KR, Wouters EF. Total free living energy expenditure in patients with severe chronic obstructive pulmonary disease. Am J Respir Crit Care Med. 1997;155:549-554.

10. Slinde F, Ellegård L, Grönberg AM, Larsson S, Rossander-Hulthén L. Total energy expenditure in underweight patients with severe chronic obstructive pulmonary disease living at home. Clin Nutr. 2003;22:159-165.

11. Patel SA, Benzo RP, Slivka WA, Sciurba FC. Activity monitoring and energy expenditure in COPD patients: a validation study. COPD. 2007;4:107-112.

12. Cavalheri V, Donária L, Ferreira T, et al. Energy expenditure during daily activities as measured by two motion sensors in patients with COPD. Respir Med. 2011;105:922-929.

13. Farooqi N, Slinde F, Håglin L, Sandström T. Validation of SenseWear Armband and ActiHeart monitors for assessments of daily energy expenditure in free-living women with chronic obstructive pulmonary disease. Physiol Rep. 2013;1(6): 00150.

14. Waschki B, Kirsten A, Holz O, et al. Physical activity is the strongest predictor of all-cause mortality in patients with COPD: a prospective cohort study. Chest. 2011;140:331-342.

15. Pitta F, Troosters T, Probst VS, Spruit MA, Decramer M, Gosselink R. Quantifying physical activity in daily life with questionnaires and motion sensors in COPD. Eur Respir J. 2006;27(5):1040-1055.

16. Schneider PL, Crouter S, Bassett DR. Pedometer measures of free-living physical activity: comparison of 13 models. Med Sci Sports Exerc. 2004;36:331-335.

17. Tudor-Locke C, Sisson SB, Lee SM, Craig CL, Plotnikoff RC, Bauman A. Evaluation of quality of commercial pedometers. Can J Public Health. 2006;97 Suppl 1:S10-S16. English, French.

18. Tudor-Locke C, Hatano Y, Pangrazi RP, Kang M. Revisiting "how many steps are enough?" Med Sci Sports Exerc. 2008;40(7 Suppl): S537-S543.

19. Furlanetto KC, Bisca GW, Oldemberg N, et al. Step counting and energy expenditure estimation in patients with chronic obstructive pulmonary disease and healthy elderly: accuracy of 2 motion sensors. Arch Phys Med Rehabil. 2010;91:261-267.

20. http://www.goldcopd.org [homepage on the Internet]. Global initiative for chronic obstructive lung disease. Available from: http://www. goldcopd.org. Accessed February 12, 2009. 
21. A healthy lifestyle, BMI [webpage on the Internet]. Geneva: World health organization. Available from: http://www.euro.who.int/en/whatwe-do/health-topics/disease-prevention/nutrition/a-healthy-lifestyle/ body-mass-index-bmi. Accessed February 15, 2009.

22. Harris JA, Benedict FG. A biometric study of basal metabolism in man. Washington, DC: Carnegie Institute; 1919.

23. Schofield WN. Predicting basal metabolic rate, new standards and review of previous work. Human Nutr Clin Nutr. 1985;39 Suppl 1: $5-41$.

24. Food and Agricultural Organization, World Health Organization, United Nations University. Energy and Protein Requirements. Report of a Joint FAO/WHO/UNU Expert Consultation World Health Organization Technical Report Series 724. Geneva, Switzerland: WHO; 1985.

25. Moore JA, Angelillo VA. Equations for the prediction of resting energy expenditure in chronic obstructive lung disease. Chest. 1988; 94:1260-1263.

26. Henry CJ. Basal metabolic rate studies in humans: measurement and development of new equations. Public Health Nutr. 2005; 8(7A):1133-1152.

27. Nordenson A, Grönberg AM, Hulthén L, Larsson S, Slinde F. A validated disease specific prediction equation for resting metabolic rate in underweight patients with COPD. Int J Chron Obstruct Pulmon Dis. 2010;7:271-276.

28. Johansson G, Westerterp KR. Assessment of the physical activity level with two questions: validation with doubly labeled water. Int $J$ Obes (Lond). 2008;32:1031-1033.

29. International Dietary Energy Consultancy Group. The doubly-labeled water method for measuring energy expenditure: Technical recommendations for use in humans. Vienna: International Atomic Energy Agency (IAEA), 1990.

30. Black AE, Prentice AM, Coward WA. Use of food quotients to predict respiratory quotients for the doubly-labelled water method of measuring energy expenditure. Hum Nutr Clin Nutr. 1986;40:381-391.
31. Frankenfield D, Roth-Yousey L, Compher C. Comparison of predictive equations for resting metabolic rate in healthy nonobese and obese adults: a systematic review. J Am Diet Assoc. 2005;105:775-789.

32. Cohen J. Statistical Power Analysis for the Behavioral Sciences. 2nd ed. Hillsdale, NJ: Lawrence Erlbaum Associates; 1988:79-81.

33. Landis JR, Koch GG. The measurement of observer agreement for categorical data. Biometrics. 1977;33:159-174.

34. Pirat A, Tucker AM, Taylor KA, et al. Comparison of measured versus predicted energy requirements in critically ill cancer patients. Respir Care. 2009;54:487-494.

35. Alves VG, da Rocha EE, Gonzalez MC, da Fonseca RB, Silva MH, Chiesa CA. Assessment of resting energy expenditure of obese patients: comparison of indirect calorimetry with formulae. Clin Nutr. 2009; 28:299-304

36. Reeves MM, Capra S. Predicting energy requirements in the clinical setting: are current methods evidence based? Nutr Rev. 2003;61: $143-151$.

37. Tan SY, Batterham M, Tapsell M. Comparison of methods used to predict energy requirements in a whole room calorimeter. Obes Res Clin Pract. 2010;4:e163-e246.

38. Turner LJ, Houchen L, Williams J, Singh SJ. Reliability of pedometers to measure step counts in patients with chronic respiratory disease. Jour Cardiopulm Rehab Prev. 2012;32:284-291.

39. Tudor-Locke C, Washington TL, Hart TL. Expected values for steps/ day in special populations. Prev Med. 2009;49:3-11.

40. Tudor-Locke C, Williams JE, Reis JP, Pluto D. Utility of pedometers for assessing physical activity: construct validity. Sports Med. 2004 $34: 281-291$
International Journal of COPD

\section{Publish your work in this journal}

The International Journal of COPD is an international, peer-reviewed journal of therapeutics and pharmacology focusing on concise rapid reporting of clinical studies and reviews in COPD. Special focus is given to the pathophysiological processes underlying the disease, intervention programs, patient focused education, and self management protocols.

\section{Dovepress}

This journal is indexed on PubMed Central, MedLine and CAS. The manuscript management system is completely online and includes a very quick and fair peer-review system, which is all easy to use. Visit http://www.dovepress.com/testimonials.php to read real quotes from published authors. 